\title{
DETERMINATION OF PROCESS DURATIONS ON VIRTUAL CONSTRUCTION SITES
}

\author{
Hans-Joachim Bargstädt \\ Arno Blickling \\ Construction Engineering and Management \\ Marienstr. 7A \\ Bauhaus University Weimar \\ 99423 Weimar, GERMANY
}

\begin{abstract}
The paper analyses the application of 3D gaming technologies in the simulation of processes associated with human resources and machinery on construction sites in order to determine process costs. It addresses the problem of detailing in process simulation. The authors outline special boundary conditions for the simulation of cost-relevant resource processes on virtual construction sites. The approach considers different needs for detailing in process simulation during the planning and building phase. For simulation of process costs on a construction site (contractors' view) the level of detail has to be high. A prototype for determination of process durations (and hereby process costs) developed at the Bauhaus University Weimar is presented as a result of ongoing researches on detailing in process simulation. It shows the method of process cost determination on a high level of detail (game between excavator and truck) through interaction with the virtual environment of the site.
\end{abstract}

\section{INTRODUCTION}

The increasing use of 3D technologies during the lifecycle of a building has brought up lots of new approaches for planning and simulating construction processes. In association with the developments in other industries the construction sector is on its way to reengineer the working process step by step on the basis of product lifecycle management (PLM/PDM) technologies (Bargstädt 2003). As these technologies are applied in the automotive sector one can look for a close similarity between the two industries. Besides, the process reengineering in construction should be accomplished in such a way that every process in the production chain can be reengineered using 3D technology. Till now the impetus was mainly on planning processes and also on site progress simulation, controlling or constructability reasoning (Cleveland 1989, Retik 1999, Li 2003, Dawood 2002, Fischer 1998, Cheok 2000). The idea of using games for simulation has been already investigated by
Halpin since 1970 (1971, 1976). In the following years several approaches were presented on how to simulate construction processes. Mukherjee et al. (2004) refer to a great variety of research work in the area of simulation, such as “(..) Superbid (AbouRizk 1993), STRATEGY (McCabe, Ching, and Savio 2000), ICMLS (Shawney, Mund, and Koczenasz 2001) and VIRCON (Jaafari, Manivong, and Chaaya 2001)". As Mukherjee mentions, “(..) some of these efforts have been inspired by earlier research undertakings in the area, such as CONSTRUCTO (Halpin and Woodhead 1970) and AROUSAL (Ndekugri and Lansley 1992). Simphony (Hajjar and AbouRizk 1999) and STROBOSCOPE (Martinez and Ioannou 1999) have also developed simulations that deal with construction operations like tunnelling and earthmoving." The presented prototype in this paper shows earthmoving processes. In this area the work of Martinez (1998) and Franz (2004) was analyzed.

One recurring point of interest was the question whether construction processes can be simulated on the basis of deterministic process models or not. In a discussion paper from Halpin (1993) on an article from AbouRizk and Sawhney on interactive duration estimation (1993) the author points out that "the ability to reliably define the durations of activities is key to the effective use of a wide range of scheduling and productivity models in construction management". Furthermore he states that "this has been an "achilles heel" in establishing the usefulness of networking models". Fuzzy set approaches as proposed by AbouRizk or Freundt (2005) might serve as an alternative to deterministic approaches in process modeling. As Halpin mentions (1993) the advantage is that it allows "mathematically unsophisticated personnel to interact with the computer in generating reliable approximations of activity durations in a rapid and useful way." He continues that the "addition of the fuzzy set procedure in modeling input durations formalizes the process of defining activity times and adds an element of mathematical rigor. This formalization is a welcome step in the development of more reliable time duration definition". However, the development of new interac- 


\section{Bargstädt and Blickling}

tive and real-time applications in the game development sector asks for reinvestigating the question, how construction processes and durations can be simulated. On the basis of Halpin and AbouRizk the concept described in this paper foresees that the estimator plays the simulation of the site progress in a way known from interactive real-time computer games, for example civilization simulation. To address the problem of determination in process modeling the chosen approach combines automated decision making with interactive human-based decision making (Bargstädt 2005b) and increases the level of detail in visualization and process modeling. The basic idea behind the increase of the level of detail is the belief that the duration of a process can be determined best if simulated as close to reality as possible. This requires to execute the process steps in realtime and on the highest possible level of detail. The unique selling proposition of the simulation approach is that the machine is not supposed to determine process durations by 'calculation' of statistical data or interactive query sessions with a field expert (see Halpin 1993, p. 719) but on the basis of logic analysis of real-time processes. The logic of processes is built with the game development engine and the process duration (minutes and seconds) is recorded by a 'virtual clock' depending on a human-based decision making in combination with automated logic. What also makes a difference, when using an interactive 3D-world for simulation, is the fact that the geometry of the site environment influences the decision making process and the process durations. The 'abstractness' of a theoretical mathematical method is augmented with the 'close-toreality' behavior of objects in virtual reality.

At the Bauhaus University Weimar (Chair of Construction Engineering and Management) the focus during the last year was set on reengineering the processes for cost estimation from the contractors point of view (Bargstädt 2004). The research is based on the use of interactive virtual reality environments known from the computer gaming technology. Those tools provide the developer with pre-defined algorithms that can be used for process simulation and interactivity. One big advantage is the possibility to setup the logic for the behavior of the application objects without programming code (Bargstädt 2005a, Bargstädt 2005c). This paper investigates the application of gaming software development tools with the focus on process simulation in virtual worlds with specific focus on cost estimation. It will also be discussed on which level of detail the individual steps in the construction process should be simulated. Finally, a prototype for the determination of process durations is presented and discussed.

\section{PROCESS SIMULATION}

When comparing process simulation in the stationary industry with that in the construction industry, some big dif- ferences exist. The processes in the common industry are characterized by:

- High precision: cost estimation for a new product development in the automotive industry goes parallel with the virtual simulation of the complete production process in order to determine labor costs and to assure process quality (see Figure 1, provided by Tecnomatix $\left.{ }^{\circledR}\right)$.

- $\quad$ Setup of production planning systems (PPS): these systems assure a high level of detail in process simulation. Because of the shortened time-tomarket of a product developers are forced to intensify time and knowledge in the product development before the product is launched.

- Constant quality of processes: as the personnel often can be kept as a team from project to project the quality of production processes can be assured in a better way.
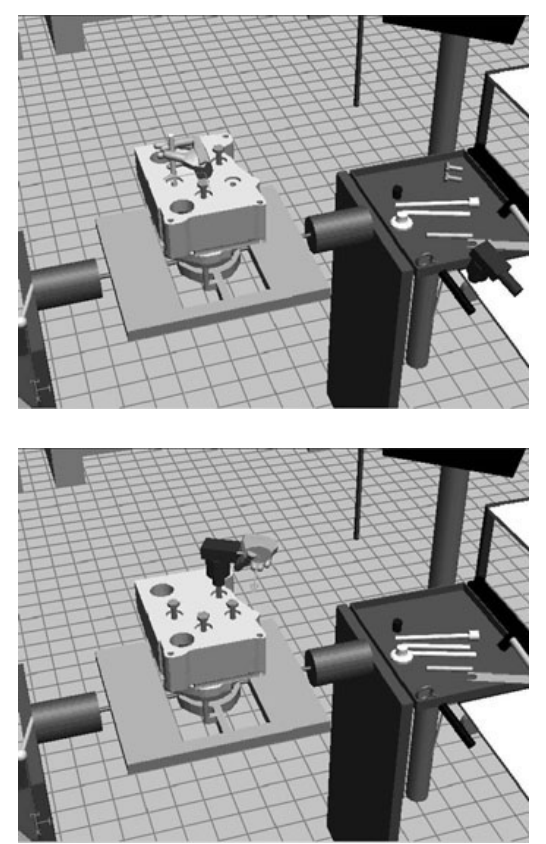

Figure 1: Assembly of Parts (Automotive Sector)

In comparison to these three arguments the process simulation in the construction industry is characterized by the following:

- Low precision: it is regarded as not feasible to simulate the whole production process in detail in advance. As a consequence the fault rate in the production process model is higher. The precision of process modeling and simulation in other industries rises from year to year, but the construction industry can hardly close up to this development (Schexnayder 1997). As nobody has yet 


\section{Bargstädt and Blickling}

defined detailed processes, the data used for estimation of process lengths are average numbers taken from single surveys or from knowledge systems.

- No specific PPS: even if a lot of efforts is taken to setup a system for production planning in the beginning of a site, practice has shown that the system will often be neglected after some period of time. The main reason is that changes in the production process model are everyday business on site. Therefore PPS known from the common industry are not always useful in construction.

- The quality of processes varies: as teams sometimes need to be established instantly, the quality of the processes may vary with people that have different levels of experience. A constant process quality can hardly be assured. It is difficult to define default processes as the boundary conditions change from site to site. Therefore the cost estimation must somehow consider the experience and the skills of the team.

The comparison shows that in the construction industry the optimization of process modeling and process simulation is crucial for higher efficiency in process quality and process controlling. A concept for production process simulation has to consider that 4D-modeling itself does not fulfill all requirements of interactivity and documentation needed. The aim of research is to handle and combine the huge amount of the single process steps in order to simulate the process costs. Therefore we first have to analyze and define different levels of detailing. What comprises high level of detail and what is low level and which level should be used in order to determine process costs?

\section{LEVEL OF DETAIL IN SIMULATION}

With the current development of 4D software tools the quality of process simulation is improving a lot. As a consequence the application of 4D today has already increased productivity (Bergsten 2003). Nevertheless there are still many problems to solve to make the use of the systems more efficient. Koo and Fischer (see Bergsten 2003) mention the deficits in simply setting up alternative scenarios in an acceptable amount of time. Also the simulation of non-physical constraints is not yet solved. Bergsten mentions the problem of detailing in process simulation saying that "(..) it is important to specify the types of operation and the level at which detailing a 4D concept provides the most benefit." It means the necessity to classify the process types to be simulated (should only the production be simulated or also other processes like site visits of surveyors?) and to choose a level of detail before simulating. Especially the latter decision has a significant effect on the complexity of the process simulation and the amount of rendered data for the performance of the simulation system. The following two examples visualize different levels of detailing in process modeling.

\subsection{Different Levels of Detailing}

It seems obvious that the owner of a project has a different view on the project than an architect or a contractor. Therefore only the data necessary for the owners' decision making should be visualized by choosing a role from a predefined set of roles. The following example (Figure 2) shows the simulation of the site progress for a simple housing. The level of detail in simulation is chosen to fit the needs of the owner who wants to see the progress milestones. The owner is merely interested in the detailed production process of every single construction unit. He wants to be able to detect major deviations when checking the site, while in contrary a contractor want to know in detail the technical aspects for the deviation.
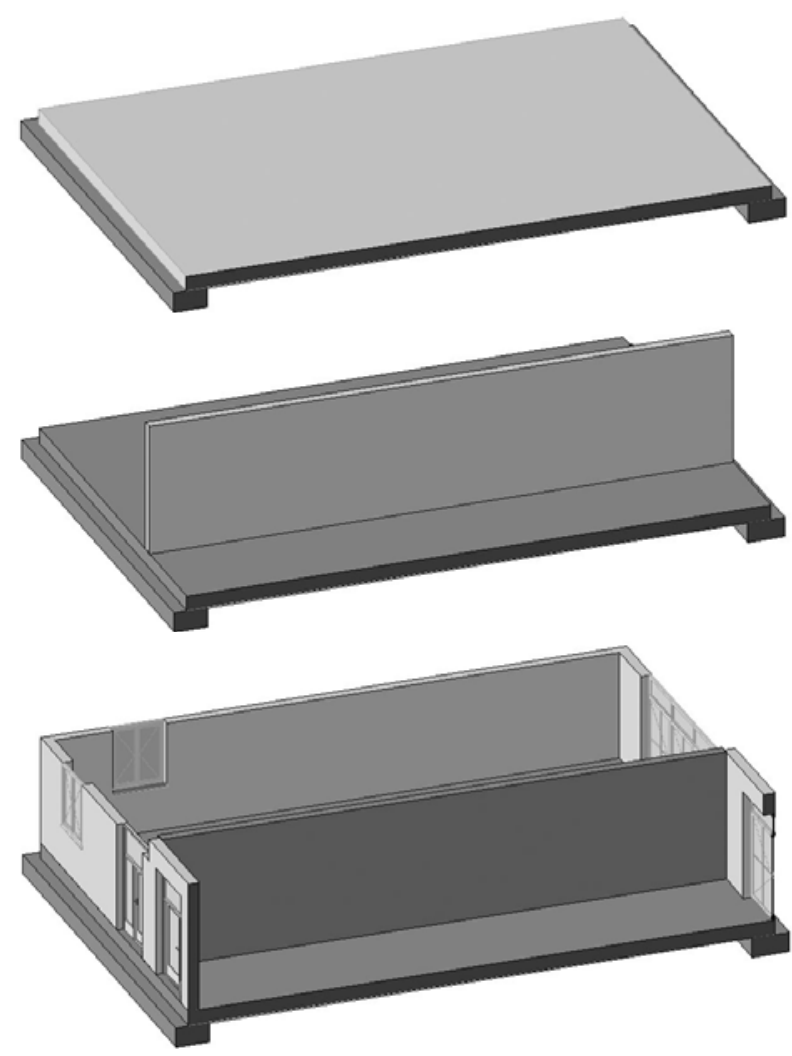

Figure 2: Low Level of Detail in Simulation

Only a few main steps of site progress may be simulated. The next sequence of simulation steps, Figure 3 shows a level of detail that might fit the needs of a foreman on the construction site looking at his working place. Instead of using drawings he might take a look on the screen of his mobile device to see what comes next in the produc- 


\section{Bargstädt and Blickling}

tion. Now the detailing is augmented so that the foreman can see which material is needed and how the working process might proceed. Here the different qualities in process execution may become visible. It depends on how experienced a worker is to estimate how much time a process would take. Thus there is a need to determine in which detail the site progress has to be simulated.
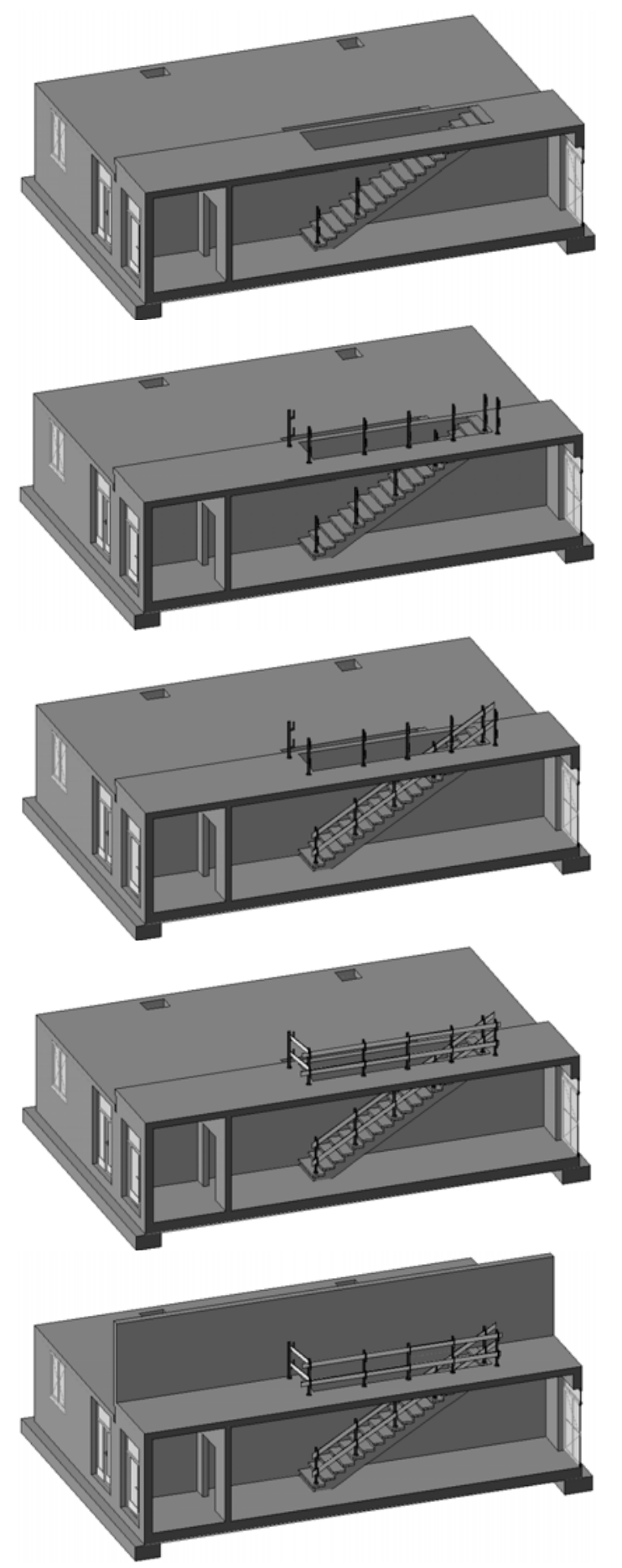

Figure 3: Medium Level of Detail in Simulation
Yet the maximum level of detail is not achieved. The requirements of the contractor to determine the expected costs from the simulated process need to be incorporated in detail. Here we face an increased complexity because of two reasons: first the simulator needs deep knowledge of construction processes and simulation technologies; second the near-real environment prompts the user to simulate the entire chain of construction processes rendering the simulation process inefficient. Even if at a first glance it appears to be inefficient, the approach for the prototype foresees that the level of detail in process simulation fulfills the requirements as described below.

\subsection{Requirements of Detailing in order to Determine Process Costs}

4D modeling is an effective method to visualize site progress by linking the $3 \mathrm{D}$ geometry of the model with the chronological activities on a time schedule. This approach may be useful for users who are not building experts or engineers or who look for a holistic view of the project. On the other hand the worker on the construction site needs to simulate less elements but with a maximum level of detail in process simulation. Therefore, the possibility to blend out the simulated processes of other disciplines is needed, that might hinder their work. If this is not done, the rendering time for the process simulation is getting too long because building parts that are not necessary are rendered as well. In the example shown in Figure 3 a lot of other processes may run simultaneously with the simulated processes. While working on the problem shown in our example the worker does not need to see the simulation for the construction of a concrete wall that might be of interest for another worker working on the site. For this reason the first requirement for detailing from the estimators point of view is the possibility to make a selection of processes to be simulated.

The second requirement for detailing is to reduce the amount of processes to shorten simulation time for the estimator. An example might be the process of driving a nail into a wall. It is clear that the worker needs a tool. The process of getting that tool for example can be estimated automatically after having determined some boundary conditions for the site such as distance to the tool magazine. Figure 4 shows a test environment for the assembly of a masonry wall. The worker is displayed as an avatar. The concept foresees that the only thing the estimator has to do is telling the worker to start building the wall. The logic of the game assures that the necessary processes are executed automatically. The worker needs tools, materials like mortar and stones and his hands. The game logic is designed in such a way that the assembly of a masonry wall of type $\mathrm{x}$ (certain stone size, mortar) requires specific steps. First the worker has to get his tools, then he needs materials and finally his hands. The worker goes to the machinery con- 


\section{Bargstädt and Blickling}

tainer, takes his tools and brings them in front of the wall. Then he goes to the stone storage, takes some stones and starts to build the wall one stone after the other. Even if there remain a lot of unanswered questions, this example shows that the logic can be used in a flexible way, what distinguishes it from purely mathematical approaches. We can now increase the distance of mortar and stones to the wall very quickly and during runtime to see that the process durations will be longer. But what really makes the difference is the possibility to play with the automated processes by using intelligent algorithms like path-finding. If we move the stones for example to another storey, the worker will automatically try to find a way to that place and the 'virtual clock' will record how long this will take.

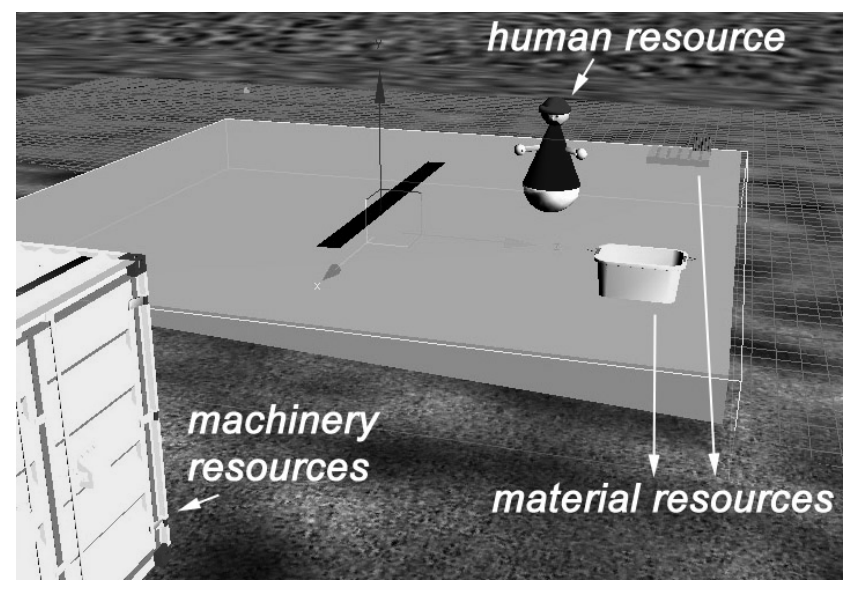

Figure 4: Building a Masonry Wall on a Virtual Site

Finally, the third requirement of detailing is to define a 'leading process': the process with a high influence on the production process chain and its efficiency. When one compares, for example, on one hand the construction process of a masonry wall with stones provided at the working place (crane lift directly to working place) and on the other hand with the process of building the same wall in a cellar (no crane access), the process of getting the stones is a 'leading process' because it has a big impact on working efficiency and the production chain is strongly dependent from it. By linking all 'leading processes' together it is possible to decrease the amount of simulation steps in estimation. The 'leading process' of a VR-based simulation is comparable to the critical path in a time schedule.

\subsection{Results regarding Cost Estimation}

Simulation of production processes on site is not the same as 4D modeling. 4D modeling is rather comparable to the animation of site progress but is not enough to simulate the production process. For cost estimation we need to simulate the production process on a high level of detail to determine process durations. Today this process is limited to the imagination and expertise of the estimator. The method can be improved by simulating the production process in a virtual environment using game technology. With these requirements in mind the following method is proposed.

\section{SIMULATING COST ESTIMATION}

In association with the latest research at the Chair of Construction Engineering and Management at the Bauhaus University in Weimar (Bargstädt 2003, Bargstädt 2004, Bargstädt 2005a, b, c) the concept of estimation foresees the simulation of every used resource in virtual reality. That means 'avatars' are used for simulating human resource activities in virtual reality. In this connection, reference can be made to the research at the Department of Building and Real Estate at the Hong Kong Polytechnic University and the Department of Civil Engineering at Tsinghua University in Beijing (Li 2003). This paper integrates avatars in the virtual environment of the construction site. It refers to an experiment that investigated benefits from using VR in supporting assembly planning. It was found out that "(..) planners spent much longer time in the traditional engineering environment than in the VR environment." Li also refers to other researchers who investigated management systems in VR with impetus on performance management and evaluation of productivity. In association with this Li proposes a knowledge-based VR system called Virtual Construction Laboratory (VCL). This system is said to enable the planner to conduct virtual experiments of innovative construction technologies and processes. The approach aims to gain productivity rates and resource information from the system. Correlated with VCL this paper discusses the simulation of human resource activities on a high level of detail to determine process durations and associated process costs during simulation of production processes. By doing so the labor costs can be estimated while playing the production process on a site as a computer game by linking resources with processes (Bargstädt 2004). A main question is concerning the accuracy of the process chain. The cost estimation process in construction foresees that the estimator determines a specific time-based effort for the related working process, for example hours $/ \mathrm{m} 2$ or hours $/ \mathrm{m} 3$. Such values are taken as average values. This theoretical assumption doesn't consider the following aspects:

1. Risks and variations in the working environment.

2. Complementary production steps that may influence productivity, e.g. distance to specific resources such as electric power, water, material.

3. Accessibility of working place, e.g. use of elevators in high-rise building.

The above list can yield a large number of constraints that depend on the building type, the topology of the site, the 


\section{Bargstädt and Blickling}

infrastructure and so on. To be able to estimate time durations it is necessary to consider a maximum number of such aspects. Just playing the production process in the estimators imagination is not very reliable for the approximate estimation of process durations. Here the use of VR environments plays a remarkable role, as this technology makes it possible to visualize the production process step by step even for other persons. With the proposed solution a huge amount of single process steps needs to be simulated in order to define an ideal production process. Until now research was focused on the visualization of the construction progress rather than on single process steps done by single workers. Nevertheless Li (2003) admits thinking about simulating virtual humans when integrating avatars directly into the virtual reality environment, but does not further develop this idea. This step is a possibility to escape from fuzzy benchmarking methods. A concept for future estimation and controlling is given in Figure 5. The output of the logic simulation of processes on a high level of detail delivers precious data about process durations and qualities.

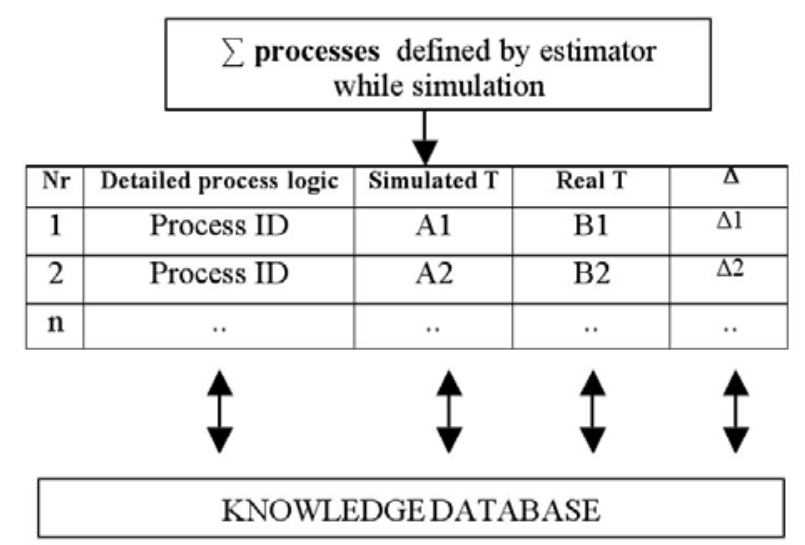

Figure 5: Benchmarking in Process Durations

It has not yet been investigated how long the simulation of all the production processes in virtual environments on a high level of detail will take. When using pre-defined algorithms for process simulation it depends on the amount of algorithms provided. Game development tools come with a large collection of pre-defined algorithms, but not all do fulfill the specific needs of construction. Let us for the time being assume that these construction-specific algorithms have been developed and are offered in our game development tool. In this case the estimator can navigate through the list of algorithms and choose one to connect it to the avatars in the virtual environment. The estimation of one single process will take only a few seconds.

Another important aspect is the method for simulating the process logic. This problem can partly be solved using pre-defined algorithms delivered with game software tools. These algorithms simulate almost all processes in VR that human beings and other objects from reality can accomplish. Nevertheless there is potential for optimization, for example through logic combination of algorithms. As an example for process logic may serve the masonry work. The process 'build masonry of type $x$ ' requires repetitive steps in the process chain. It is assumed that the bricklayer is standing in one place and the bricks are stored a few meters away from him. To build a brick wall he needs to walk to the position where he can get stones from the pile, take some stones and go back. Then he places them in the wall after having added some mortar. As this is a repetitive process with a certain number of variables the process logic for 'build masonry of type $\mathrm{x}$ ' can be developed. The position of the stones is one of several variables that need to be determined or calculated from the drawings.

\section{PRESENTATION OF THE PROTOTYPE}

The prototype presented below was developed using Quest3D®. Quest3D® delivers full simulation functionality without any code programming, but also offers a developers ' kit. For more complex simulations on a high level of detail it will be necessary to develop construction-specific algorithms. At this time we did not experience the functionalities of the developers' kit, but used only the predefined algorithms included in the enterprise edition.

Here the game between an excavator and a truck had to be simulated in real-time. For this the requirements were defined as follows:

1. Excavator and truck types are selected out of a machinery database.

2. The machinery database contains all detailed data on the chosen machine, e.g. cost/hour, max. load.

3. Logic is used from the first prototype on to handle movements of objects in the virtual environment.

4. The virtual time should be displayed in the application window as well as the buttons to start and stop duration recording during simulation.

5. The determined durations are saved in an external database for later evaluation.

6. The virtual construction site should provide the user with basic geometrical data on the site, that means the object should appear in a close to reality shape.

The second prototype requires deeper knowledge of the channel graph logic. All in all the application consists of several channel groups which merge to one big graph. It is not possible to show the whole graph in this paper, as the complexity is too high. In the following only some aspects of the graph are discussed. Further details on the graph logic have been published at CIB-W78 $\left(22^{\text {nd }}\right.$ Conference Information Technology in Construction) in July (Bargstädt 2005a). 


\section{Bargstädt and Blickling}

One problem was to set up a 'virtual time system'. This system is supposed to assure the real-time character of the application. The movements of the truck and the excavator should be as fast as in reality. The velocity of the excavator in comparison to the truck is much slower, which means, that the truck has to wait for the excavator from time to time. This should be considered in the virtual environment, as if it were reality in order to ensure the authenticity of the system. The actual time should be displayed for the user. Figure 6 shows a part of the 'clock channel' as implemented in the application. It displays simple button logic for 'start' and 'stop'. A further task was the implementation of the logic to decide on the machines to be used for simulation. After the start of the application the system asks for the machine types. The user can go through all the machines in the database and thus determine the configuration consisting of one excavator and one truck.

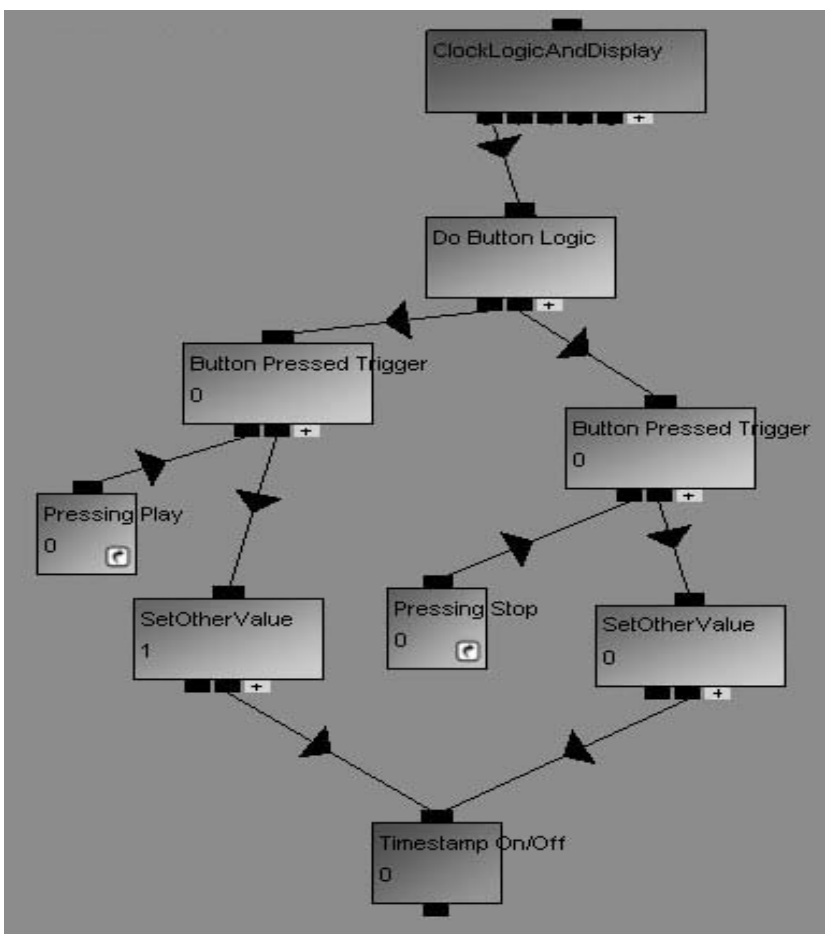

Figure 6: Channel Graph for the 'Virtual Clock System'

Here the system lets the user decide, which truck or excavator to choose, but considers the maximum performance possible with the chosen configuration of machines. The selection process is kept open for human decision instead of decisions, which are generated automatically by the system.

Figures 7-10 show screenshots of the application. Figure 7 shows the startup window with the menu of available trucks and excavators. In addition to the truck and the excavator the user can also choose specific equipment of the excavator, e.g. size and type of the excavator shovel. Of course only compatible equipment is offered by the database.

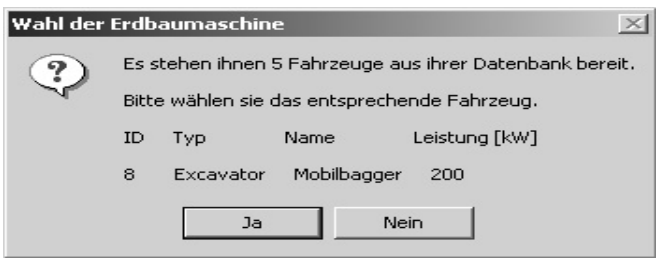

Figure 7: User Dialog during Choice of Excavator

Figure 8 shows the situation after the determination of excavator, equipment and truck. In this prototype the user can only vary the geometrical position of the working environment. Yet for the time being the shown excavation is only a 'play process' because other logic has not been implemented. The next step foresees the determination of a point on the ground of the virtual construction site.

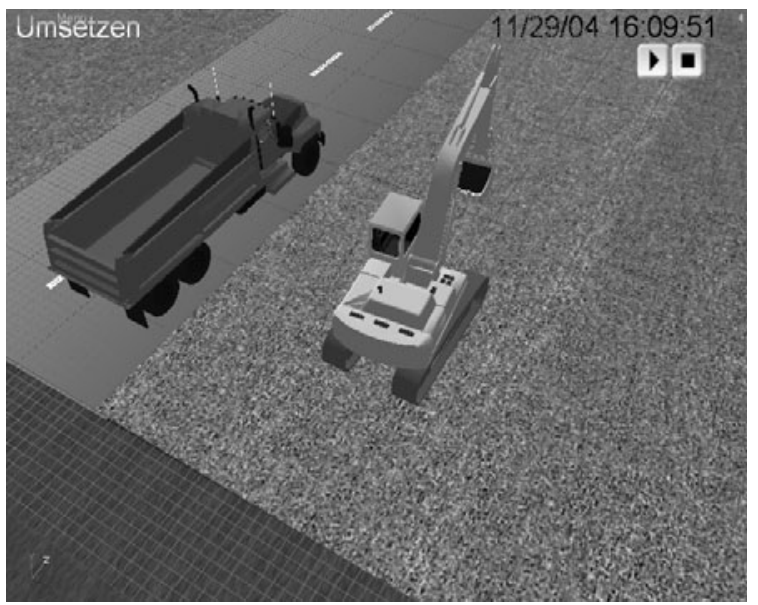

Figure 8: Startup Window of Simulation Tool

The user indicates the position on the screen, where subsequently the machine will move to. In Figure 9 this position is marked by a cube.

After having reached the desired position, both machines stop and wait for further user input. In the actual construction phase the user can switch from hauling ( Umsetzen ' in Figure 8) to dig and load. This change in phases is important for the database to register, that a certain process type is finished. After each phase the time system saves the process duration and waits for the next process to begin. After having changed the phase the user needs to specify the position of the digging area. This can be initiated by user input and causes the excavator to rotate the shovel to the chosen position. The dig process can also be started by user input. After this the movements of the excavator are animated in real-time, which is important for the correct 


\section{Bargstädt and Blickling}

determination of the process duration. Here the prototype is not yet designed to consider changes in the geometry of the ground area, after the shovel has hit the ground.

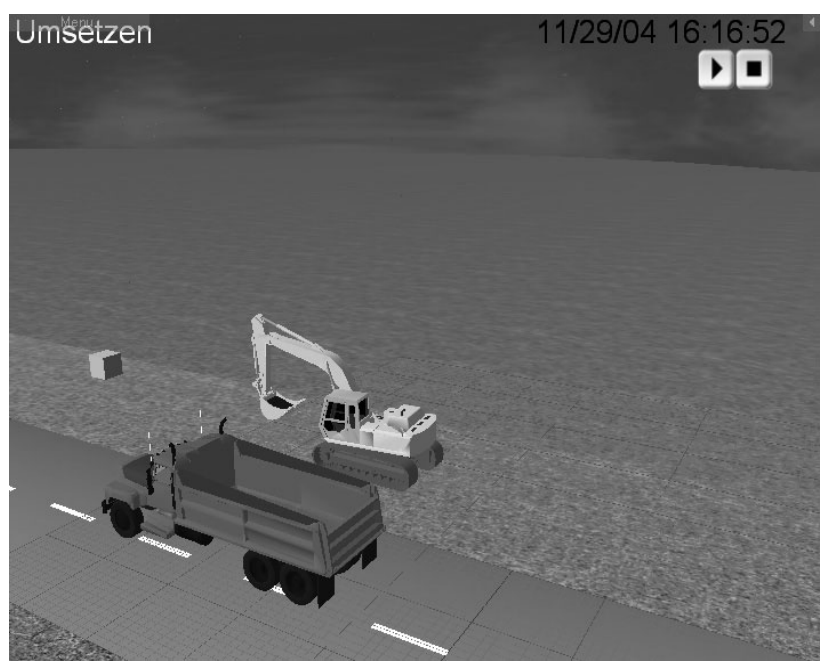

Figure 9: Machines Move to 'Cube Location'

After having performed all the necessary steps to fill up the truck (the truck can only leave, when filled up completely), it moves automatically to the unloading point. Before that the phase changes to process-dependent waiting for discharge (Ablaufbedingtes Warten durch Abladen in Figure 10), which is another process phase to be considered in the database.

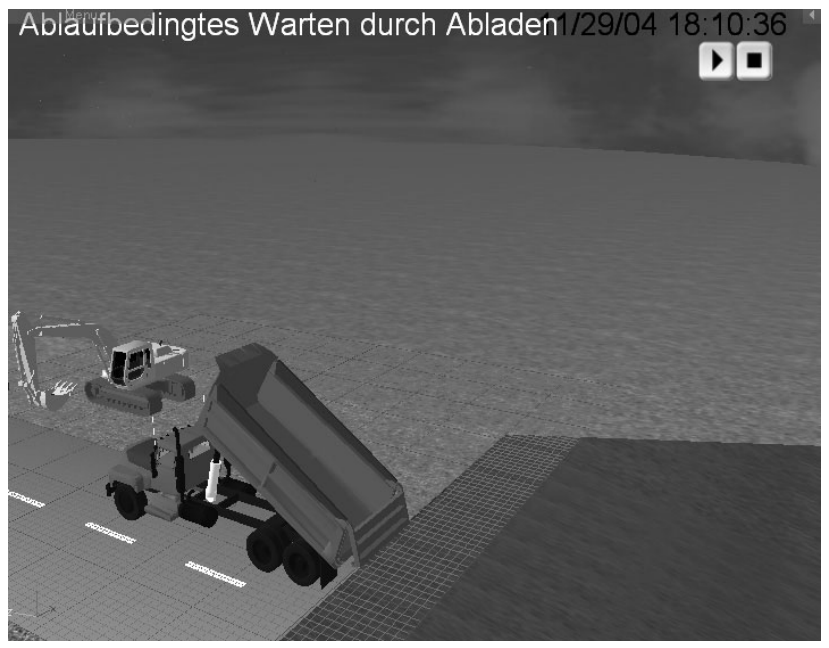

Figure 10: Filled up Truck Moves to Unloading Point

The process as described above can be executed in "simulation mode" (process durations are instantly written in the database) or offline. Clicking the 'play' button starts the simulation mode. The actual process phase is identified and written into the database together with the start- ing/ending time of the process and its ID. The database then calculates the difference between starting and ending time and thus the process duration. Figure 11 shows an example of data written into the database.

In this stage of the prototype 'leading processes' are not implemented. Therefore the user has to initiate the change in phases manually by interacting with the system. With the data shown in Figure 11 the prototype has achieved its aim. The process durations can now be multiplied by the cost parameter of the single objects (e.g. $E U R / h$ ) in the virtual environment to determine the resource costs for certain processes. As one can see, the process duration for dig and load (Baggern und Beladen in Figure 11) is 5:31 minutes, which is quite a long time to wait for in front of a computer screen.

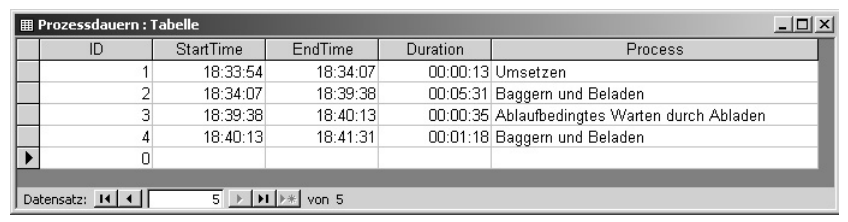

Figure 11: Processes and Durations in the Database

However, this is the 'real time the excavator will need for executing the process. The commitment to 'real' time process simulation is due to the necessity to simulate some process types in the construction area in one by one steps. Even if not considered in this work, it is clear that the coexistence of non-simulated and simulated processes is necessary to avoid long waiting times. In this context a time accelerator can compress the simulation velocity. On the other hand it has not been investigated yet, which effect this might have on the logic, because when accelerating time some decisions have to be made automatically or by slowing down at 'decision points'. To further develop this idea a concept for a partly automated simulation approach will be presented at CONVR (5th International Conference on Construction Applications of Virtual Reality) in September 2005 (Bargstädt 2005b).

\section{PROS AND CONS}

The paper summarizes current research on gaming technology at the chair of Construction Engineering and Management at the Bauhaus University Weimar. First experiences allow to evaluate the pros and the cons as follows.

\subsection{Cons}

One disadvantage of the described method is the duration of the estimation process for the user of the system. If the level of detail is at its maximum and there is no possibility to minimize the amount of processes to be simulated the estimated total time for playing 'one cost estimation game' 


\section{Bargstädt and Blickling}

is quite long compared to the current cost estimation process. A possible solution will be to minimize the amount of processes to be simulated manually and to reroute a maximum number of processes to the computer where those processes can be simulated automatically on the basis of pre-defined logic. Today we have to admit that the practicability of the suggested approach is not yet given because the logic needed to have a flexible prototype for different process types is not developed yet. This will be subject of further research work in the area of interactive real-time environments for process modeling on construction sites. The next steps foresee to include masonry processes as well as other process types.

Furthermore the library of pre-defined algorithms is not yet adapted to the specific needs of the construction industry. This requires the development of every single process step from the beginning on to the reusable channel graph. Once the graph is developed it can be reused. If reusability is possible the development of constructionspecific graphs is a worthwhile investment.

Also the building sector has not been considered yet, because when it comes to the assembly of the 3D parts of the new construction it will be necessary to develop a concept for importing the 3D parts from a CAD system into the virtual environment of the site. This requires access to the $3 \mathrm{D}$ parts database together with a user interface that allows the navigation through the $3 \mathrm{D}$ model in order to identify the requested parts.

\subsection{Pros}

The major advantage gained from a virtual construction site is the quality of the visualized process. Our first prototype (balls and cube) this advantage is not observable because the environment is yet too simple. By simulating on a higher level of detail we obtain close-to-reality data which allow to make more reliable assumptions on the real process durations. This takes risk out of the cost estimation process and leads to a more accurate cost estimation.

Furthermore the proposed estimation method combines process simulation with process cost estimation. As the virtual time system allows to record the duration of processes the total time for certain process categories (e.g. answers the question: how much time have we spent on 'digging and loading' or 'changing position '?) can be analyzed easily. Also the process costs can be calculated by the computer derived from the process simulation during the play of the game. Today the cost estimation process is separate from the simulation process, which costs a lot of time and may lead to misunderstandings between cost estimator and the site manager. Through the merge of these two processes precious time can be saved.

The cost estimator is forced to think deeper about possible problems in the production chain, because the virtual environment communicates problems immediately and closer to reality because of its visual interface.

With the technology it is also possible to pause the cost estimation process in real-time for a while and continue later. This is relevant when the estimator is interrupted in his work.

A great advantage of the system is, that it is easy-touse for other persons who get involved into the construction process in a later phase of the project. In a short time those users can watch the pre-planned construction process and use it as guidance.

\section{CONCLUSIONS}

Virtual reality in construction calls for reengineering the construction processes accurately, especially for the purpose of reliable cost estimation and controlling. Even if today process simulation and thus determination of process durations and costs are not very detailed, the ongoing development of new VR-based approaches will facilitate that higher level of detailing in construction process simulation. With the tool from above new applications of virtual environments in construction are possible, such as controlling on a daily basis directly on the construction site. It is expected that the ease of use together with the 'game character' of the method will lead to a higher acceptance of computer based methods on construction sites. The presented ideas and concepts will be pursued at the chair of Construction Engineering and Management at the Bauhaus University Weimar. The aim is also to bundle the worldwide approaches for construction process simulation correlated with cost estimation and controlling and - in future also with transportation and logistics in order to establish a valuable basis for the construction industry. A further focus will also be set on the development of process logic for site-relevant construction process simulation.

\section{REFERENCES}

AbouRizk, S.M., Sawhney, A. 1993. Subjective and interactive duration estimation. Canadian Journal of Civil Engineering 20(3): 457-470.

Bargstädt, H.-J., Blickling, A. 2003. Unit-oriented tendering and calculation of buildings using data generated by the method of Integrated Product Lifecycle management (PLM/PDM) of buildings. IABSE-Symposium Metropolitan Habitats and Infrastructure, Shanghai 2004. Available via http://www.uniwei-

mar. de/Bauing/baubet/personen/blickl ing_engl.html [accessed July 29, 2005].

Bargstädt, H.-J., Blickling, A. 2004. Effective cost estimate and construction processes with $3 \mathrm{D}$ interactive technologies: Towards a virtual world of construction sites. Xth International Conference on Computing in 


\section{Bargstädt and Blickling}

Civil and Building Engineering ICCCBE, Weimar, June 2-4, 2004. Available via http: / / www. uniwei-

mar. de / Bauing / baubet/personen/blickl ing_engl.html [accessed July 29, 2005].

Bargstädt, H.-J., Blickling, A. 2005a. Implementation of logic for earthmoving processes with a game development engine. In Proceedings of Information Technology in Construction, 22nd CIB-W7,8 Dresden 1921 July 2005, see http://cib.bau.tudresden. de/w78/ [accessed July 28, 2005].

Bargstädt, H.-J., Blickling, A. 2005b. A game prototype for determination of construction process parameters with a partly automated simulation approach. Paper submitted at CONVR 2005 in Durham (UK), to be held from 12-13 September 2005, see http : / / www . adetti.pt / events / CONVR2 00 5 [accessed July 29, 2005].

Bargstädt, H.-J., Blickling, A. 2005c. Simulation of construction processes with game development software. Poster accepted at International Scientific Colloquium, 50th IWK 2005, Ilmenau (Germany), Faculty of Mechanical Engineering, to be held from 19-23 September 2005, see http://www.iwk.tuilmenau. de [accessed June 13, 2005].

Bergsten, S. 2003. Using 4D CAD in the design and management of vertical extensions to existing buildings. In: Construction Process Improvement, ed. Atkin, Brian; Borgbrant, Jan; Josephson, Per-Erik), 266-277. Oxford: Blackwell Science.

Cheok, G.S., Stone, W.C., Lipman, R.R., Witzgall, C. 2000. Ladars for construction assessment and update. Automation in Construction, 9: 463-473.

Cleveland, A.B. Jr. 1989. Real-time animation of construction cctivities. In Proceedings of Construction Congress I - Excellence in the Constructed Project. 238243. San Francisco, CA: ASCE.

Dawood, N., Sriprasert, E., Mallasi, Z., Hobbs, B. 2002. Development of an integrated information resource base for 4D/VR construction processes simulation. In Automation in Construction. 12: 123-131.

Fischer, M., Staub, S. 1998. Constructability reasoning based on a 4D facility model. In Proceedings of Structural Engineering Worldwide. Elsevier Science Ltd.

Franz, V., Chahrour, R. 2004. Computer Simulation in Civil Engineering - State of the Art, Innovative Application Fields. In Proceedings of 11. ASIM Dedicated Conference - Simulation in Production and Logistics. 329-339. Fraunhofer Institute for Production Systems and Design Technology (IPK). Berlin.

Freundt, M. 2005. Ein flexibles Modell für die Bauablaufplanung auf Basis von Graphentheorie und FuzzyZahlen. Aachen: Shaker. Doctoral dissertation, Bauhaus-University Weimar, 2004.
Halpin, D. W. 1971. CONSTRUCTO - A computerized construction game. In Proceedings of Annual Meeting American Society for Engineering Education (ASEE), Annapolis, Maryland. Event 69: 1-14.

Halpin, D. W. 1976. CONSTRUCTO - An interactive gaming environment. Journal of the Construction Division, ASCE. 102(C01): 145-156.

Halpin, D. W. 1993. Subjective and interactive duration estimation: Discussion. Canadian Journal of Civil Engineering. 20(4): 719-721.

Li, H., Ma, Z., Shen, Q., Kong, S. 2003. Virtual experiment of innovative construction operations. Automation in Construction, 12(5): 561-575.

Martinez, J.C. 1998. Earthmover - Simulation tool for earthwork planning. In Proceedings of the 1998 Winter Simulation Conference. Society for Computer Simulation. Washington, D.C.

Mukherjee, A., Rojas, E.M., Winn, W.D. 2004. Implementing a general purpose framework using multiagents for construction management education. In Proceedings of the 2004 Winter Simulation Conference, 1244-1251.

Retik, A., Shapira, A. 1999. VR-based planning of construction site activities. Automation in Construction. 8: 671-680.

Schexnayder C.J. 1997. Analysis of earth-moving systems using discrete-event simulation. Discussion. Journal of Construction Engineering and Management. 121: 199.

\section{AUTHOR BIOGRAPHIES}

HANS-JOACHIM BARGSTÄDT is professor and head of the Chair of Construction Engineering and Management at Bauhaus University Weimar, Germany. His research interests include virtual construction sites, simulation and 4D modeling in construction, supply chain management and logistics in construction as well as aspects of international project management. His e-mail address is <hansjoachim. bargstaedtabauing . uni-

weimar.de> and his Web address is <www.uniweimar.de/Bauing/baubet/index.html>.

ARNO BLICKLING is an assistant researcher at the Chair of Construction Engineering and Management at Bauhaus University Weimar, Germany. Before he was construction manager in a building company. His research interests include the application of game development tools for process simulation on virtual construction sites. His email address is carno.blickling@bauing.uniweimar.de> and his Web address is <www.uniwei-

mar. de/Bauing/baubet/personen/blickling _engl.html>. 